\title{
Changes in Environmental Footprints Associated with Dietary Intake of Lebanese Adolescents between the Years 1997 and 2009
}

\author{
Farah Naja ${ }^{1}$, Nahla Hwalla ${ }^{1}$, Anas El Zouhbi ${ }^{2}$, Nada Abbas ${ }^{1}$, Marie Claire Chamieh ${ }^{1}$, \\ Lara Nasreddine ${ }^{1, *}$ and Lamis Jomaa $1, * \mathbb{D}$ \\ 1 Department of Nutrition and Food Sciences, Faculty of Agricultural and Food Sciences, American University \\ of Beirut, 1107-2020 Beirut, Lebanon; fn14@aub.edu.lb (F.N.); nahla@aub.edu.lb (N.H.); \\ na280@aub.edu.lb (N.A.); mc31@aub.edu.lb (M.C.C.) \\ 2 Department of Biology, Faculty of Arts and Sciences, American University of Beirut, 1107-2020 Beirut, \\ Lebanon; ahe32@mail.aub.edu \\ * Correspondence: ln10@aub.edu.lb (L.N.); lj18@aub.edu.lb (L.J.)
}

Received: 30 March 2020; Accepted: 27 April 2020; Published: 2 June 2020

\begin{abstract}
Despite global efforts to promote healthy and sustainable diets, the nutrition transition witnessed among adolescents worldwide poses serious threats to health and environmental sustainability. The present study aimed to assess the change in environmental footprints (EFPs) associated with dietary intakes of adolescents in Lebanon between 1997 and 2009. Data of Lebanese adolescents (10-19 years old) were drawn from national food consumption surveys during two time periods (1997, $\mathrm{n}=451 ; 2009, \mathrm{n}=527)$. Dietary assessments were conducted using 24-h dietary recalls. EFP metrics, including water, energy and greenhouse gas emissions (GHG), were derived using review of existing life-cycle analyses. All EFPs increased significantly between 1997 and 2009; meat and sugar-sweetened beverages were the top contributors to the increase in these EFPs. The changes in EFPs between the two years remained significant even after adjustment for energy and other correlates: water ( $\beta=267.7, \mathrm{CI}$ : $123.5 ; 411.9$ ); energy ( $\beta=4.3, \mathrm{CI}: 2.09 ; 6.52)$ and GHG ( $\beta=0.44, C I: 0.11 ; 0.76)$. Findings show significant dietary shifts among adolescents that can threaten the environmental sustainability of Lebanese diets. Interventions across the food system are needed to promote adherence to healthy and sustainable diets among adolescents.
\end{abstract}

Keywords: dietary intake; trend; environmental footprints; sustainable diets; Mediterranean diet; adolescents; Lebanon

\section{Introduction}

Dietary choices and food consumption are considered key drivers of health and environmental outcomes [1,2]. According to the United Nations (UN) sustainable development agenda, responsible food consumption and production represent key opportunities to ensure proper and efficient use of resources, reduce environmental and economic burdens, and improve quality of life for all people [3]. "Sustainable diets" were placed at the forefront of this agenda; referring to diets with low environmental impacts that can contribute to food and nutrition security and to healthy life for present and future generations. Sustainable diets have also been described as protective and respectful of biodiversity, economic fairness and affordability, as well as cultural acceptability, and nutritional safety and adequacy [4]. Although extensive evidence exists linking dietary intake to health and environmental sustainability, there was no consensus until recently as to what can be considered as a low environmental impact diet. The Eat-Lancet Commission proposed such a diet to consist largely of vegetables, fruits, whole grains, legumes, nuts, and unsaturated oils; with low to moderate amounts of seafood and 
poultry. In addition, the diet proposed to have low environmental footprint included no or a low quantity of red meat, processed meat, added sugar, refined grains, and starchy vegetables [5].

Despite the extensive global efforts to achieve more sustainable diets and to promote nutrition and food security through a sustainable food system, achieving such goals remains a challenge amidst the current trends and trajectories of diets [6]. The trend in the average global diet remains one in which energy, in the form of refined carbohydrates, sugar and fats is increasing, while in parallel, the availability and consumption of nutrient-rich foods, including fruits, vegetables, and whole gains is suboptimal [7]. This global shift in food systems, characterized by a drift away from traditional, diverse and balanced diets towards more processed and energy-dense diets, has been linked with increased risk of obesity and non-communicable diseases across higher and lower-income countries and as a driver of decreased environmental sustainability [8].

In addition to potential adverse health outcomes, the current food consumption patterns have been shown to have detrimental effects on the environment. It is argued that the highly industrialized and resource-intensive agricultural and food production systems that promote the consumption of animal-based diets and highly processed foods are key contributors to environmental damage, including land degradation, loss of freshwater and biodiversity, and climate change [9]. The industrialization of the global food production system was also held responsible for almost $70 \%$ of water use, one of the most significant causes for diminishing biological diversity through deforestation, and it was estimated to contribute to $20-30 \%$ of all greenhouse gas emissions (GHGs) [10]. In this context, several environmental footprint (EFP) indicators were developed to assess the environmental impact of human diets, including GHG emissions (carbon footprint), water use (green water, blue water and grey water), land use as well as other ecological and chemical footprints [11]. These EFPs provide a way to examine diets through the water, energy, GHG and health nexus lens, which is considered as a fundamental step towards achieving sustainable food consumption in various populations [12].

Amidst the global changes in food systems, the Eastern Mediterranean Region (EMR) is witnessing the nutrition transition, with its characteristic shift in food consumption patterns, away from the traditional patterns towards westernized eating habits and practices [13]. These changes in diets may be particularly pronounced amongst adolescents in the region, who may be more exposed to and influenced by food environmental factors related to the nutrition transition, such as food advertising and promotion, the consumption of energy-dense, processed "fashionable" foods, and the adoption of unhealthy eating behaviors such as increasingly eating out at fast food outlets and consuming convenience foods away from home [14,15]. Adolescence is increasingly viewed as a key developmental stage for ensuring health across the lifespan, and may provide significant opportunities to improve population health in the EMR in the short as well as the long term [16,17]. In the EMR region, adolescents represent more than a quarter of the population in the region, and ensuring proper nutrition in this life stage is necessary for adequate physical and biological growth as well as optimal cognitive development [17]. In addition, it is during this critical stage that adolescents establish their lifelong health and dietary behaviors [18].

In Lebanon, a small country of the EMR, available evidence suggests that the dietary intake of adolescents is shifting away from the traditional diet rich in fruits, vegetables, legumes, and olive oil towards a more energy-dense westernized diet $[19,20]$. In parallel, and like many other countries in the EMR, Lebanon is struggling with escalating diet-related diseases including diabetes, hypertension and cardiovascular diseases [21,22] coupled with pressing environmental challenges including water scarcity and poor management of natural resources that are threatening its population's health and food security [23-25]. Therefore, it is important to examine whether the ongoing shifts in dietary intakes amongst adolescents are also associated with an adverse impact on environment sustainability. The present study aims to assess the change in environmental footprints (EFPs) associated with shifts in dietary intakes of adolescents over different time points in Lebanon. 


\section{Materials and Methods}

\subsection{Study Design and Protocol}

In order to examine the changes over time in the EFPs associated with food consumption of Lebanese adolescents (aged 10-19 years), data derived from two national cross-sectional food consumption surveys conducted in Lebanon during two time periods were used: 1997 and 2009.

\subsubsection{Original Surveys}

- Design and Protocol

The sampling framework and data collection protocols used in these surveys are published elsewhere [20]. Both surveys were conceptualized, designed, overseen, and conducted by the same research group at the American University of Beirut. The surveys were population-based, and nationally representative of Lebanese participants aged 6 years, and older. A stratified cluster sampling was used as a sampling frame in both surveys, with the household being the primary sampling unit. From each household, one adult and one child/adolescent were invited to participate. In case more than one eligible subject was identified, only one was selected at random.

The 1997 survey was conducted on a subsample of the Lebanese Population Health Survey (PHS) participants. In the PHS, the strata were the population conglomerations, which included cities, town and groups of villages with small population size. The country was divided into 637 conglomerations. Within each population conglomeration, geographical enclaves were considered as clusters. On average, each population conglomeration included 4284 geographical enclaves, of which 1422 were drawn at random. Fifty households were selected at random from each geographical enclave. As such, the number of households participating in the PHS was 61,580 with a response rate of $95.5 \%$. For the 1997 survey, 1\% of these households were selected at random and invited to participate. The total number of participants in the 1997 survey was 2004, of who 451 were adolescents.

For the 2009 survey, the governorates of Lebanon constituted the various strata and the districts within governorates were considered as clusters. Within each district, households were selected at random. The number of households drawn from each cluster was proportional to the size of the corresponding cluster. The response rate in this survey was $89.3 \%$, the total number of participants was 3636 subjects. The protocols of both surveys were approved by the Institutional Review Board of the American University of Beirut. Before participation, informed consent/assent of participants were documented.

\section{- $\quad$ Data Collection}

For both surveys, through face-to-face interview, trained field workers, who underwent extensive training, collected the data at the participants' house. The training of the field workers aimed to ensure the standardization of their interviewing techniques and minimizing any interviewer's bias. The duration of the interview ranged between 45 and $60 \mathrm{~min}$. Data collection included the completion of a multicomponent sociodemographic and lifestyle questionnaire, anthropometric measurements and dietary intake assessment. Common to the questionnaires used in the two surveys were age (in years), sex (males, females), governorate of residence, mother's and father's education levels (intermediate or less, high school or technical diploma and university or higher), in addition to the crowding index, used as a proxy for socioeconomic status [26,27]. The anthropometric measurements obtained were weight $(\mathrm{kg})$ and height $(\mathrm{m})$. Each measurement was taken twice, and the average reading was used in the analysis. Description of the protocols used for these measurements are described elsewhere [20,28].

The dietary assessment of study participants was carried out using 24-h dietary recall. Each participant was asked to describe in detail the foods and beverages he/she has consumed during the previous $24 \mathrm{~h}$. These details included type of food, its method of preparation and the amount consumed. Field workers were trained to probe participants about specific food items that are 
usually omitted or forgotten. These foods include various kinds of condiment (ketchup, mayonnaise, mustard and added fats and oils). For the estimation of the amount of food consumed, the participants were given the choice to indicate it in grams or standard portion size. Real size photos as well as food models were used to describe the standard portion size of some foods. Dietary intakes, as collected from the 24-h recall, were entered into and analyzed using The Nutritionist Pro software (Nutritionist Pro, Axxya Systems, San Bruno, CA, version 5.1.0, 2014). Within this software, the USDA database was selected to carry out the dietary analysis (SR 24, published September 2011). Local and mixed dishes were added to the database using standardized recipes of single food items. Total energy intake was estimated as the sum of energy provided by the various foods consumed. Dieticians who have received extensive training on dietary intake data entry and analysis were responsible for the use of the Nutritionist Pro software and the handling of the dietary intake data. Dietary intake assessment took place on random days during the week. Days following national holidays and feasts were avoided.

\subsubsection{Data Used in This Study}

Sociodemographic, anthropometric and dietary data of adolescents aged 10 to 19 years were drawn for the surveys of 1997 and 2009 ( $n=451$ and $n=527$, respectively) and were used in the current analysis. The geographical distributions of adolescents in both surveys were proportional to that of the Lebanese population $[29,30]$, as shown in Table 1.

Table 1. Comparison of the distributions (\%) of the study samples in years 1997 and 2009 with those of national estimates.

\begin{tabular}{ccccc}
\hline Governorates & $\begin{array}{c}\text { National }{ }^{\mathbf{a}, *} \\
\mathbf{1 9 9 7}\end{array}$ & $\begin{array}{c}\text { Study Sample } \\
\mathbf{( 1 9 9 7 )}\end{array}$ & $\begin{array}{c}\text { National } \\
\mathbf{( 2 0 0 9 )}\end{array}$ & $\begin{array}{c}\text { Study Sample } \\
\mathbf{( 2 0 0 9 )}^{\mathbf{2 0 0 9}}\end{array}$ \\
\hline Beirut and Mount Lebanon & 44.11 & 53.21 & 46.74 & 46.03 \\
North & 22.11 & 12.42 & 21.56 & 24.18 \\
Bekaa & 14.78 & 16.41 & 13.08 & 13.73 \\
South & 19.00 & 17.96 & 18.61 & 16.05 \\
\hline
\end{tabular}

a Central Administration of Statistics. Household Living Conditions in 1997, a national survey. Beirut; 1998;

$\mathrm{b}$ Central Administration of Statistics Bureau. Multiple Indicators Cluster Survey round 3 (MICS3), 2009. Beirut;

$2010 ;{ }^{*}$ The national data that was available as reference for year 1997 belonged to adolescents aged 15-19.

In addition to the datasets derived from the original surveys, for this this study, a new data set that corresponds to the EFPs associated with dietary intake of Lebanese adolescents participating in both surveys was used. The water use, energy use as well as GHG emissions were estimated using a review of existing life-cycle analyses (LCAs). These EFPs were calculated for each $1 \mathrm{~kg}$ of the food items/groups consumed (see S1). The detailed methodology used in the estimation of these EFPs is published elsewhere [31,32]. Briefly, the LCAs conducted in Mediterranean or neighboring countries that possess a comparable climate to Lebanon were selected and used in the estimation of EFPs.

The water footprint in this study included blue and green water and was expressed in terms of $(\mathrm{L} / \mathrm{kg})$. These calculations took into consideration the water stress index (WSI) as well as domestically versus imported proportions of each of the food items [33,34]. For the latter, the two main countries by amount from where a certain food is imported were included [35]. Accordingly, the formula used to calculate water use was as follows:

Water use $=($ Water use $\times \%$ produced $\times$ WSI Lebanon $)+($ Water Use $\times \%$ imported Total $\times$ $\%$ importedCountry $1 \times$ WSICountry 1$)+($ Water Use $\times \%$ imported Total $\times \%$ importedCountry $2 \times$ WSICountry2).

Energy use associated with food consumption was expressed in $\mathrm{MJ} / \mathrm{kg}$ of food consumed while $\mathrm{kg} \mathrm{CO} 2 \mathrm{eq} / \mathrm{kg}$ food consumed was the metric used to quantify GHG emissions. In the case of GHG estimations, $\mathrm{LCAs}$ reporting $\mathrm{CH}_{4}$ and $\mathrm{N}_{2} \mathrm{O}$ were included and their estimations were converted to $\mathrm{CO}_{2}$ equivalent using the following conversions [36]:

$$
\mathrm{CO}_{2 e q \mathrm{~N}_{2} \mathrm{O}}=\mathrm{X}_{\mathrm{N}_{2} \mathrm{O}} \times G W P_{\mathrm{N}_{2} \mathrm{O}}
$$




$$
\mathrm{CO}_{2 e q} \mathrm{CH}_{4}=\mathrm{X}_{\mathrm{CH}_{4}} \times \mathrm{GWP}_{\mathrm{CH}_{4}}
$$

$\mathrm{X}_{\mathrm{N}_{2} \mathrm{O}}: \mathrm{N}_{2} \mathrm{O}$ released (kg); $\mathrm{X}_{\mathrm{CH}_{4}}: \mathrm{CH}_{4}$ released $(\mathrm{kg}) ; G W P_{\mathrm{N}_{2} \mathrm{O}}$ and $G W P_{\mathrm{CH}_{4}}$ refer to the 100-year global warming potential of $\mathrm{N}_{2} \mathrm{O}$ and $\mathrm{CH}_{4}\left(\mathrm{~N}_{2} \mathrm{O}: 265, \mathrm{CH}_{4}\right.$ : 28) [36].

\subsection{Statistical Analyses}

Data entry and analysis were conducted using IBM SPSS for Windows (version 25, IBM Corp., Armonk, NY, USA) and Stata/SE (version 13, StataCorp, College Station, TX). Descriptive statistics were presented as mean \pm standard error (SE) and proportions representing continuous and categorical variables, respectively. Differences in sociodemographic and anthropometric characteristics by survey year were examined using independent sample $t$-test and chi-square test. Differences among the two survey years with regards to dietary intakes from various food groups (expressed as grams and \% contribution to energy intake) were examined using independent $t$-test. The EFPs (water, energy and GHG footprint) were estimated by multiplying, for each participant, the intake (in kilograms) of each food group by its corresponding EFPs impact (in S1). EFPs' mean \pm SE were then calculated, adjusted for kilocalories intake (/1000 kcal) and compared between the two surveys using independent sample $t$-test. Percent contribution of each food group to the total change in EFPs between the two survey years were also calculated. In order to examine the correlates of EFPs, including sociodemographic characteristics and year of survey, simple and multiple linear regression analyses were conducted. For each EFP, a simple and a multiple regression models were carried out. For both models, the EFP estimate was the dependent variable. In the simple regression model, the survey years and sociodemographic characteristics were considered as independent variables. For the multiple regression models, in addition to age and sex, only variables which were found to be significantly associated with the dependent variable were entered as independent variables. Results from the linear regression models were expressed as $\beta$ coefficients with $95 \%$ confidence intervals. Statistical significance was set at a $p$-value lower than 0.05 .

\section{Results}

\subsection{Sociodemographic and Anthropometric Characteristics of the Study Population}

Table 2 describes the frequency distribution of sociodemographic and anthropometric characteristics by survey years (1997 and 2009). The sample included 978 adolescents aged between 10-19 years (451 participants in year 1997 and 527 in year 2009). In the overall sample, the proportion of female participants was slightly higher than males ( $54.3 \%$ vs. $45.7 \%$, respectively) and the majority $(76.8 \%)$ had a crowding index of two or more persons per room. The sex and crowding index distribution did not vary significantly between the two years. Adolescents belonging to the 2009 survey were significantly older as compared to those belonging to the 1997 survey (mean age $14.61 \pm 0.11 \mathrm{vs}$. $14 \pm 0.12$ years, $p<0.001$ ). Body mass index (BMI), father's education and governorate distributions were significantly different between the two survey years $(p<0.0001)$. The proportions of participants having a father with a university degree or higher and residing in Beirut were lower in 2009 compared to 1997. The prevalence of obesity among study participants was higher in 2009 compared to 1997 $(12.3 \%$ vs. $3.9 \%)$. Education level of the mother for almost half of the participants was intermediate or less (57.2.\%) with no significant difference between the two survey years.

\subsection{Dietary Intake of the Study Population}

Study participants' daily intake of the various food groups expressed as grams and percent contribution to total energy is presented in Table 3. Results showed that energy adjusted intake (\%kcal) of milk and fruits significantly decreased in 2009 as compared to 1997 (from $1.97 \pm 0.19$ to $1.34 \pm 0.18$ for milk and from $6.05 \pm 0.36$ to $3.65 \pm 0.26$ for fruits). On the other hand, the intakes (\%kcal) of salty snacks, meat, poultry and added fats/oils increased significantly in year 2009 compared to 1997 
(salty snacks: from $2.46 \pm 0.27$ to $4.56 \pm 0.37$; meat: from $5.95 \pm 0.48$ to $7.99 \pm 0.65$; poultry: from $1.44 \pm 0.23$ to $3.13 \pm 0.35$; added fats/oils: from $2.8 \pm 0.22$ to $5.75 \pm 0.35$ ), Table 3 .

Table 2. Sociodemographic characteristics of Lebanese adolescents by survey year.

\begin{tabular}{|c|c|c|c|c|}
\hline Subjects' Characteristics & $\begin{array}{c}\text { Total } \\
(\mathrm{N}=978)\end{array}$ & $\begin{array}{c}1997 \\
(n=451)\end{array}$ & $\begin{array}{c}2009 \\
(n=527)\end{array}$ & $p$-Value \\
\hline Age (years) $($ Mean $\pm S E)$ & $14.33 \pm 0.08$ & $14 \pm 0.12$ & $14.61 \pm 0.11$ & $<0.001$ \\
\hline Males & $447(45.71)$ & $194(43.02)$ & $253(48.01)$ & \multirow[b]{2}{*}{0.118} \\
\hline Females & $531(54.29)$ & $257(56.98)$ & $274(51.99)$ & \\
\hline \multicolumn{5}{|c|}{ Governorate } \\
\hline Beirut and Mount Lebanon & $478(49.38)$ & $240(53.21)$ & $238(46.03)$ & \multirow{4}{*}{$<0.001$} \\
\hline Bekaa & $145(14.98)$ & $74(16.41)$ & $71(13.73)$ & \\
\hline North & $181(18.7)$ & $56(12.42)$ & $125(24.18)$ & \\
\hline South & $164(16.94)$ & $81(17.96)$ & $83(16.05)$ & \\
\hline \multicolumn{5}{|c|}{ Crowding Index } \\
\hline$<2$ persons/room & $750(76.77)$ & $350(77.61)$ & $400(76.05)$ & \multirow{2}{*}{0.554} \\
\hline$\geq 2$ persons/room & $227(23.23)$ & $101(22.39)$ & $126(23.95)$ & \\
\hline \multicolumn{5}{|c|}{ Mother's education level } \\
\hline Intermediate or less & $531(57.16)$ & $274(60.75)$ & $257(53.77)$ & \\
\hline High school or Technical diploma & $251(27.02)$ & $106(23.5)$ & $145(30.33)$ & 0.05 \\
\hline University or more & $147(15.82)$ & $71(15.74)$ & $76(15.9)$ & \\
\hline \multicolumn{5}{|c|}{ Father's education level } \\
\hline Intermediate or less & $502(56.53)$ & $204(48)$ & $298(64.36)$ & \\
\hline High school or Technical diploma & $193(21.73)$ & $102(24)$ & $91(19.65)$ & $<0.001$ \\
\hline University or more & $193(21.73)$ & $119(28)$ & $74(15.98)$ & \\
\hline \multicolumn{5}{|c|}{ BMI category } \\
\hline Underweight/Normal weight & $688(70.34)$ & $337(74.73)$ & $351(66.6)$ & \multirow{3}{*}{$<0.001$} \\
\hline Overweight & $207(21.17)$ & $96(21.29)$ & $111(21.06)$ & \\
\hline Obese & $83(8.49)$ & $18(3.99)$ & $65(12.33)$ & \\
\hline
\end{tabular}

Abbreviations: BMI: body mass index; SE: standard error. Data are expressed as mean \pm SE for age and as absolute numbers and percentages for the remaining sociodemographic variables. Differences among group means were tested by independent sample $t$-test (for continuous variables) and chi-square test (for categorical variables). Numbers in bold are statistically significant $(p$-value $\leq 0.05)$. BMI was stratified according to the World Health Organization (WHO) Growth Standards (WHO 2007).

\subsection{Changes in Environmental Footprints (EFPs) Associated with Dietary Intake of the Study Population} between 1997 and 2009

Between 1997 and 2009, the overall EFPs associated with daily food consumption of Lebanese adolescents increased significantly (water use: $1908.28 \pm 52.43$ to $2358 \pm 62.49$ L/day, energy use: $25.31 \pm 0.7$ to $31.32 \pm 0.91 \mathrm{MJ} /$ day and GHG: $3.01 \pm 0.1$ to $3.66 \pm 0.13 \mathrm{~kg} \mathrm{CO}_{2} \mathrm{eq} /$ day) (S2). The EFPs associated with daily food consumption of various foods and food groups are presented in Table S2. Table 4 presents the energy adjusted EFPs (per $1000 \mathrm{Kcal}$ ) associated with daily dietary intake of Lebanese adolescents. After adjustment for energy, all of the EFPs increased significantly from 1997 to 2009. Compared to estimates in 1997, water use, energy use and GHG increased significantly in 2009 for the following groups: Breads and cereals, poultry, fish, salty snacks, and sugar-sweetened beverages (SSBs). On the other hand, the EFPs associated with milk and fruits consumptions decreased significantly in 2009 as compared to 1997. 
Table 3. Average daily food intake (in grams and \%kcal) of the sample contributed by various food groups by survey year among Lebanese adolescents.

\begin{tabular}{|c|c|c|c|c|c|c|c|c|}
\hline \multirow{3}{*}{ Food Group } & \multicolumn{8}{|c|}{ Intake } \\
\hline & \multicolumn{3}{|c|}{ Grams/Day } & & & \multirow{2}{*}{$\begin{array}{r}\% \text { Kcal/Day } \\
2009\end{array}$} & \multirow[b]{2}{*}{$p$-Value } & \multirow[b]{2}{*}{ Change (\%Kcal/Day) } \\
\hline & 1997 & 2009 & $p$-Value & Change (g/Day) & 1997 & & & \\
\hline Total energy (kcal/day) & $1861.05 \pm 32.31$ & $2053.89 \pm 34.974$ & $<0.001$ & 192.84 & - & - & - & - \\
\hline Breads and Cereals & $183.45 \pm 6.9$ & $224.87 \pm 9.02$ & $<0.001$ & 41.42 & $24.1 \pm 0.74$ & $25.26 \pm 0.75$ & 0.276 & 1.16 \\
\hline Meat & $47.35 \pm 4.04$ & $61.06 \pm 4.73$ & 0.029 & 13.71 & $5.95 \pm 0.48$ & $7.99 \pm 0.65$ & 0.013 & 2.04 \\
\hline Poultry & $13.99 \pm 2.2$ & $30.19 \pm 3.65$ & $<0.001$ & 16.2 & $1.44 \pm 0.23$ & $3.13 \pm 0.35$ & $<0.001$ & 1.69 \\
\hline Fish & $3.26 \pm 1.24$ & $10.69 \pm 2.38$ & 0.006 & 7.43 & $0.3 \pm 0.12$ & $0.65 \pm 0.13$ & 0.051 & 0.35 \\
\hline Eggs & $18.02 \pm 1.95$ & $15.43 \pm 3.48$ & 0.529 & -2.59 & $1.7 \pm 0.18$ & $1.37 \pm 0.42$ & 0.494 & -0.33 \\
\hline Milk & $54.98 \pm 5.32$ & $14.25 \pm 2.38$ & $<0.001$ & -40.73 & $1.97 \pm 0.19$ & $1.34 \pm 0.18$ & 0.015 & -0.63 \\
\hline Sweetened Dairy Products & $5.87 \pm 1.69$ & $7.4 \pm 2.25$ & 0.600 & 1.53 & $0.46 \pm 0.14$ & $0.5 \pm 0.16$ & 0.861 & 0.04 \\
\hline Legumes & $37.42 \pm 7.61$ & $50.05 \pm 6.79$ & 0.191 & 12.63 & $2.76 \pm 0.39$ & $3.3 \pm 0.45$ & 0.373 & 0.54 \\
\hline Starchy Vegetables & $48.34 \pm 3.65$ & $59.62 \pm 4.55$ & 0.056 & 11.28 & $5.86 \pm 0.42$ & $5.14 \pm 0.33$ & 0.165 & -0.72 \\
\hline Vegetables & $176.15 \pm 8.32$ & $191.5 \pm 12.73$ & 0.302 & 15.35 & $6.51 \pm 0.37$ & $6.17 \pm 0.53$ & 0.586 & -0.34 \\
\hline Fruits & $184.17 \pm 10.39$ & $114.75 \pm 7.8$ & $<0.001$ & -69.42 & $6.05 \pm 0.36$ & $3.65 \pm 0.26$ & $<0.001$ & -2.4 \\
\hline Fresh Fruit Juices & $1.78 \pm 1.3$ & $3.55 \pm 1.45$ & 0.374 & 1.77 & $0.03 \pm 0.02$ & $0.07 \pm 0.03$ & 0.389 & 0.04 \\
\hline Nuts & $9.11 \pm 1.55$ & $6.92 \pm 1.28$ & 0.268 & -2.19 & $2.27 \pm 0.31$ & $1.61 \pm 0.29$ & 0.115 & -0.66 \\
\hline Salty Snacks b & $9.44 \pm 1.03$ & $17.91 \pm 1.44$ & $<0.001$ & 8.47 & $2.46 \pm 0.27$ & $4.56 \pm 0.37$ & $<0.001$ & 2.1 \\
\hline Sugar sweetened beverages (SSB) ${ }^{c}$ & $241.42 \pm 13.97$ & $322.35 \pm 13.9$ & $<0.001$ & 80.93 & $5.83 \pm 0.35$ & $7.15 \pm 0.31$ & 0.005 & 1.32 \\
\hline Hot Beverages & $116.96 \pm 8.72$ & $83.92 \pm 6.22$ & 0.002 & -33.04 & $0.14 \pm 0.03$ & $0.1 \pm 0.02$ & 0.191 & -0.04 \\
\hline Fast Food $^{\mathrm{d}}$ & $77.52 \pm 5.58$ & $95.51 \pm 7.37$ & 0.050 & 17.99 & $10.68 \pm 0.77$ & $12.75 \pm 1.06$ & 0.117 & 2.07 \\
\hline Added Fats / Oils & $9.06 \pm 0.8$ & $18.74 \pm 1.48$ & $<0.001$ & 9.68 & $2.8 \pm 0.22$ & $5.75 \pm 0.35$ & $<0.001$ & 2.95 \\
\hline Soups/broth/Condiments/Pickles & $11.41 \pm 2.18$ & $16.21 \pm 3.01$ & 0.213 & 4.8 & $0.5 \pm 0.11$ & $0.5 \pm 0.08$ & 0.977 & 0.004 \\
\hline
\end{tabular}

Data are expressed as mean \pm SE. Differences among group means were tested by independent sample $t$-test. ${ }^{a}$ Including dairy products and yoghurt based dishes. ${ }^{\mathrm{b}}$ Including chips, salty crackers, popcorn. ${ }^{c}$ Including sweetened fruit juices/beverages, fruit drinks and regular soft drinks. ${ }^{d}$ Ready to eat sandwiches, burgers, pizzas and pies. 
Table 4. Daily environmental footprints [water, energy and greenhouse gas emissions adjusted for energy intake (/1000 kcal/day)] contributed by various food groups intake by survey year (1997 and 2009) among Lebanese adolescents aged 10-19 years.

\begin{tabular}{|c|c|c|c|c|c|c|c|c|c|}
\hline \multirow{3}{*}{ Food Group } & \multirow{2}{*}{\multicolumn{2}{|c|}{$\begin{array}{c}\text { Water Use } \\
\text { (L/1000 Kcal/Day) }\end{array}$}} & \multirow{3}{*}{$p$-Value } & \multirow{2}{*}{\multicolumn{2}{|c|}{$\begin{array}{c}\text { Energy Use } \\
\text { (MJ/1000 Kcal/Day) }\end{array}$}} & \multirow{3}{*}{$p$-Value } & \multirow{2}{*}{\multicolumn{2}{|c|}{$\begin{array}{c}\begin{array}{c}\text { Green House Gas (GHG) } \\
\text { Emissions }\end{array} \\
\text { (kg CO}_{2} \text { eq/1000 Kcal/Day) }\end{array}$}} & \multirow{3}{*}{$p$-Value } \\
\hline & & & & & & & & & \\
\hline & 1997 & 2009 & & 1997 & 2009 & & 1997 & 2009 & \\
\hline Breads and Cereals & $63.3646 \pm 2.9840$ & $83.4408 \pm 4.4536$ & $<0.001$ & $1.6907 \pm 0.0658$ & $1.9072 \pm 0.0746$ & 0.030 & $0.115 \pm 0.0058$ & $0.1546 \pm 0.0086$ & $<0.001$ \\
\hline Meat & $216.3534 \pm 17.5432$ & $265.6403 \pm 20.7087$ & 0.075 & $1.0408 \pm 0.0844$ & $1.2779 \pm 0.0996$ & 0.075 & $0.4938 \pm 0.04$ & $0.6062 \pm 0.0473$ & 0.075 \\
\hline Poultry & $24.0406 \pm 3.6715$ & $48.5903 \pm 5.5794$ & $<0.001$ & $0.1624 \pm 0.0248$ & $0.3283 \pm 0.0377$ & $<0.001$ & $0.0269 \pm 0.0041$ & $0.0545 \pm 0.0063$ & $<0.001$ \\
\hline Fish & $2.1323 \pm 0.7609$ & $5.6007 \pm 1.1349$ & 0.011 & $0.1366 \pm 0.0488$ & $0.3588 \pm 0.0727$ & 0.011 & $0.006 \pm 0.0021$ & $0.0157 \pm 0.0032$ & 0.011 \\
\hline Eggs & $27.9644 \pm 3.0075$ & $23.0547 \pm 7.3417$ & 0.560 & $0.1135 \pm 0.0122$ & $0.0936 \pm 0.0298$ & 0.560 & $0.0357 \pm 0.0038$ & $0.0294 \pm 0.0094$ & 0.560 \\
\hline Milk & $16.8036 \pm 1.6897$ & $4.5008 \pm 0.9889$ & $<0.001$ & $0.9734 \pm 0.0979$ & $0.2607 \pm 0.0573$ & $<0.001$ & $0.1135 \pm 0.0114$ & $0.0304 \pm 0.0067$ & $<0.001$ \\
\hline Milk Derivatives ${ }^{a}$ & $109.9376 \pm 7.8460$ & $88.3443 \pm 6.2848$ & 0.032 & $0.2834 \pm 0.0201$ & $0.2393 \pm 0.0172$ & 0.093 & $0.0198 \pm 0.0014$ & $0.0167 \pm 0.0012$ & 0.093 \\
\hline Sweetened Dairy Products & $2.3585 \pm 0.6869$ & $3.1827 \pm 1.0004$ & 0.511 & $0.101 \pm 0.0294$ & $0.1363 \pm 0.0428$ & 0.511 & $0.0121 \pm 0.0035$ & $0.0163 \pm 0.0051$ & 0.511 \\
\hline Legumes & $38.1793 \pm 6.5607$ & $50.0035 \pm 7.1014$ & 0.222 & $0.037 \pm 0.0064$ & $0.0485 \pm 0.0069$ & 0.222 & $0.0094 \pm 0.0016$ & $0.0123 \pm 0.0017$ & 0.222 \\
\hline Starchy Vegetables & $6.8242 \pm 0.5164$ & $7.3676 \pm 0.5452$ & 0.474 & $0.0137 \pm 0.001$ & $0.0148 \pm 0.0011$ & 0.474 & $0.0033 \pm 0.0002$ & $0.0036 \pm 0.0003$ & 0.474 \\
\hline Vegetables & $73.2175 \pm 8.1964$ & $72.4438 \pm 8.9968$ & 0.950 & $2.5102 \pm 0.1334$ & $2.4825 \pm 0.1987$ & 0.908 & $0.2375 \pm 0.0193$ & $0.2303 \pm 0.0221$ & 0.809 \\
\hline Fruits & $72.9714 \pm 4.3654$ & $39.7326 \pm 2.7912$ & $<0.001$ & $0.6326 \pm 0.0416$ & $0.3363 \pm 0.0236$ & $<0.001$ & $0.05 \pm 0.0032$ & $0.0266 \pm 0.0019$ & $<0.001$ \\
\hline Fresh Fruit Juices & $0.4683 \pm 0.3110$ & $1.0186 \pm 0.4189$ & 0.292 & $0.0097 \pm 0.0065$ & $0.0212 \pm 0.0087$ & 0.292 & $0.0006 \pm 0.0004$ & $0.0013 \pm 0.0005$ & 0.292 \\
\hline Nuts & $21.1315 \pm 3.2019$ & $15.6172 \pm 2.8004$ & 0.195 & $0.0214 \pm 0.0032$ & $0.0158 \pm 0.0028$ & 0.195 & $0.0018 \pm 0.0003$ & $0.0013 \pm 0.0002$ & 0.195 \\
\hline Salty Snacks ${ }^{b}$ & $5.7922 \pm 0.6255$ & $10.7233 \pm 0.8791$ & $<0.001$ & $0.0279 \pm 0.003$ & $0.0517 \pm 0.0042$ & $<0.001$ & $0.0025 \pm 0.0003$ & $0.0047 \pm 0.0004$ & $<0.001$ \\
\hline Sugar sweetened beverages $(\mathrm{SSB})^{\mathrm{c}}$ & $141.0652 \pm 9.3595$ & $206.1825 \pm 11.3422$ & $<0.001$ & $3.9263 \pm 0.2878$ & $5.9148 \pm 0.3566$ & $<0.001$ & $0.1794 \pm 0.0148$ & $0.2794 \pm 0.0186$ & $<0.001$ \\
\hline Hot Beverages & $8.1273 \pm 0.6215$ & $5.4772 \pm 0.4914$ & 0.001 & $0.0692 \pm 0.0053$ & $0.0466 \pm 0.0042$ & 0.001 & $0.0242 \pm 0.0019$ & $0.0163 \pm 0.0015$ & 0.001 \\
\hline Sweets & $97.6559 \pm 7.7126$ & $140.8855 \pm 12.1203$ & 0.003 & $1.0186 \pm 0.0601$ & $1.0828 \pm 0.0764$ & 0.519 & $0.0881 \pm 0.0055$ & $0.0791 \pm 0.0055$ & 0.254 \\
\hline Fast Food ${ }^{d}$ & $65.1313 \pm 7.0384$ & $64.1239 \pm 9.8780$ & 0.936 & $0.6176 \pm 0.0488$ & $0.6502 \pm 0.0653$ & 0.697 & $0.148 \pm 0.0171$ & $0.1436 \pm 0.024$ & 0.886 \\
\hline Added Fats / Oils & $18.9618 \pm 1.7533$ & $30.779 \pm 2.1448$ & $<0.001$ & $0.1445 \pm 0.0126$ & $0.3048 \pm 0.0203$ & $<0.001$ & $0.0182 \pm 0.0017$ & $0.0293 \pm 0.0021$ & $<0.001$ \\
\hline Soups/broth/Condiments/Pickles & $11.2816 \pm 2.3619$ & $10.9092 \pm 1.3538$ & 0.887 & $0.2007 \pm 0.0405$ & $0.2335 \pm 0.0406$ & 0.570 & $0.0563 \pm 0.019$ & $0.0971 \pm 0.0295$ & 0.246 \\
\hline TOTAL & $1025.8179 \pm 21.4565$ & $1182.5070 \pm 29.30214$ & $<0.001$ & $13.7841 \pm 0.3306$ & $15.9207 \pm 0.4572$ & $<0.001$ & $1.6452 \pm 0.0475$ & $1.8549 \pm 0.066$ & 0.010 \\
\hline
\end{tabular}

Abbreviations: GHG: greenhouse gases; SSB: Sugar Sweetened Beverages. Data are expressed as mean \pm SE. Differences among group means were tested by independent sample $t$-test.

${ }^{a}$ Including dairy products and yoghurt-based dishes. ${ }^{b}$ Including chips, salty crackers, popcorn. ${ }^{c}$ Including sweetened fruit juices/beverages, fruit drinks and regular soft drinks. ${ }^{d}$ Ready to eat sandwiches, burgers, pizzas and pies. 
The contribution (\%) of the various food groups to the change in water use, energy use and GHG between 1997 and 2009 are presented in Figure 1. Overall, meat, SSB, breads and cereals and poultry were among the five largest contributors to the increase in the three EFPs considered in this study.

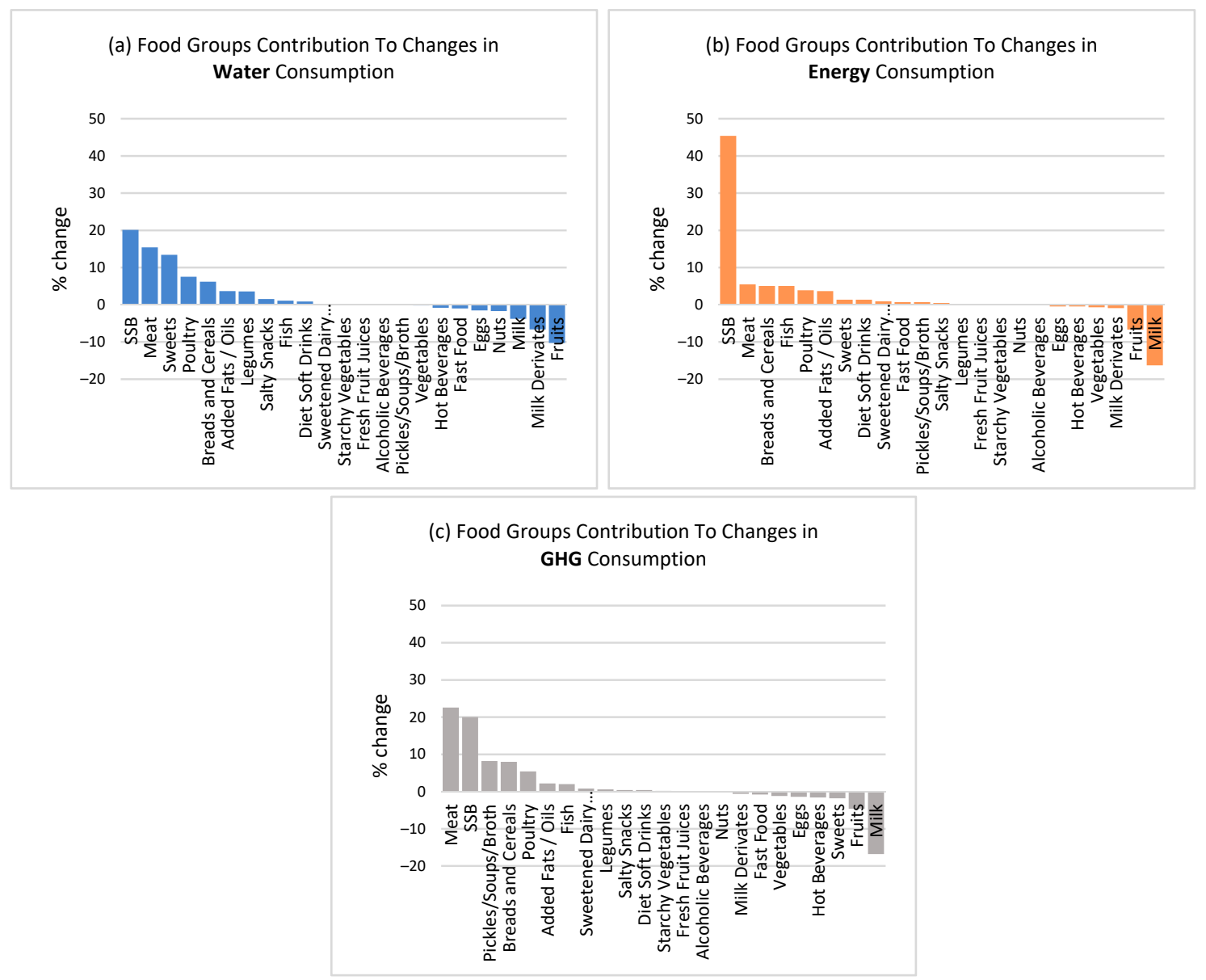

Figure 1. Food groups contribution to changes in environmental footprints of dietary intake (between 1997 and 2009) in the study sample.

Table 5 shows the results of the crude (Model 1) and adjusted (Model 2) linear regression analyses. After adjustment for age, energy, sex, governorate and mother's and father's education level, belonging to year 2009 was significantly associated with higher estimates for water use ( $\beta=267.7,95 \%$ confidence interval (CI) $(123.5 ; 411.91))$, for energy use $(\beta=4.3,95 \% \mathrm{CI}: 2.09 ; 6.52)$ and GHG $(\beta=0.44,95 \% \mathrm{CI}$ : $0.111 ; 0.769))$, as compared to belonging to year 1997. The direct effect of energy intake on EFPs was attenuated after adjustments but remained statistically significant (for water: $\beta=0.95,95 \% \mathrm{CI}$ (0.85; 1.05), for energy: $\beta=0.01,95 \% \mathrm{CI}(0.01 ; 0.01)$ and for GHG: $\beta=0.001,95 \% \mathrm{CI}(0.0001 ; 0.002)$. As for the sociodemographic characteristics, having a mother with a university degree, compared to intermediate or less, was shown to be significantly associated with higher water use and GHG; for water: $\beta=328.85,95 \% \mathrm{CI}(96.57 ; 561.13)$; for GHG: $\beta=0.683,95 \% \mathrm{CI}(0.154 ; 1.213)$. Compared to Beirut, participants residing in the South of Lebanon, had lower estimates of water and GHG use; for water: $\beta=-242.64,95 \% \mathrm{CI}(-442.56 ;-42.73)$; for GHG: $\beta=-0.63,95 \% \mathrm{CI}(-1.086 ;-0.174)$, and those residing in the Northern governorate had lower estimates of all EFPs; water use: $\beta=-334.41,95 \% \mathrm{CI}$ $(-521.52 ;-147.29)$; energy use: $-3.39 \%$ CI $(-6.27 ;-0.51)$; GHG use: $\beta=-0.716 \%$ CI $(-1.143 ;-0.29)$. 
Table 5. Linear regression for the association between environmental footprints (water, energy and GHG), survey year and sociodemographic characteristics among Lebanese adolescents.

\begin{tabular}{|c|c|c|c|c|c|c|c|c|c|c|c|c|}
\hline \multirow{4}{*}{ Subjects' Characteristics } & \multicolumn{4}{|c|}{ Water Use } & \multicolumn{4}{|c|}{ Energy Use } & \multicolumn{4}{|c|}{ GHG Emission } \\
\hline & \multicolumn{4}{|c|}{ (L/1000 Kcal/Day) } & \multicolumn{4}{|c|}{ (MJ/1000 Kcal/Day) } & \multicolumn{4}{|c|}{$\left(\mathrm{kg} \mathrm{CO}_{2} \mathrm{eq} / 1000 \mathrm{Kcal} / \mathrm{Day}\right)$} \\
\hline & \multicolumn{2}{|c|}{ Model 1 (Crude) } & \multicolumn{2}{|r|}{ Model 2} & \multicolumn{2}{|c|}{ Model 1 (Crude) } & & \multirow{2}{*}{$\begin{array}{l}\text { Model } 2 \\
\quad 95 \% \mathrm{CI}\end{array}$} & \multicolumn{2}{|c|}{ Model 1 (Crude) } & \multicolumn{2}{|c|}{ Model 2} \\
\hline & & & & $95 \% \mathrm{CI}$ & & $95 \%$ CI & Coef. & & Coet. & $95 \% \mathrm{CI}$ & Coef. & $95 \% \mathrm{CI}$ \\
\hline Survey year a 2009 & 452.5586 & $(289.4736 ; 615.6436)$ & 267.7042 & $(123.4995 ; 411.9089)$ & 6.0655 & $(3.7495 ; 8.3815)$ & 4.3047 & $(2.0881 ; 6.5213)$ & 0.6500 & $(0.3238 ; 0.9762)$ & 0.4399 & $(0.1111 ; 0.7687)$ \\
\hline Age (years) & 35.2969 & $(3.571 ; 67.0227)$ & 16.8625 & $(-10.0775 ; 43.8024)$ & 0.4654 & $(0.0154 ; 0.9153)$ & 0.1450 & $(-0.2691 ; 0$. & 0.0567 & $(-0.0064 ; 0.1197)$ & 0.0283 & $(-0.0331 ; 0.0897)$ \\
\hline Energy & 1.0308 & $(0.943 ; 1.1186)$ & 0.9491 & $(0.8503 ; 1.048)$ & 0.0127 & $(0.0114 ; 0.0140)$ & 0.0116 & $(0.0101 ; 0.0132)$ & 0.0015 & $(0.0013 ; 0.0017)$ & 0.0013 & $(0.0011 ; 0.0015)$ \\
\hline Sex ${ }^{b}$ Females & -629.5528 & $(-790.4191 ;-468.6866)$ & -117.9413 & $(-266.9604 ; 31.0778)$ & -8.0270 & $(-10.3209 ;-5.733)$ & -1.4166 & $(-3.7072 ; 0.874)$ & -1.1646 & $(-1.4852 ;-0.8439)$ & -0.4509 & $(-0.7907 ;-0.1111)$ \\
\hline \multicolumn{13}{|l|}{ Governorate $^{c}$} \\
\hline North & -245.1078 & $(-469.2363 ;-20.9794)$ & -334.4058 & $(-521.5187 ;-147.293)$ & $\begin{array}{l}-1.4820 \\
-2.5436\end{array}$ & $\begin{array}{l}(-4.97311 ; .9722) \\
(-5.72380 .06365)\end{array}$ & $\begin{array}{r}0.5916 \\
-3.3910\end{array}$ & $\begin{array}{l}(-2.55232 ; 3.7356) \\
(-6.2672 ;-0.5149)\end{array}$ & $\begin{array}{l}-0.2408 \\
-0.6022\end{array}$ & $\begin{array}{l}(-0.7238 ; ; 0.2422) \\
(-1.0468-0.1576)\end{array}$ & $\begin{array}{c}0.0061 \\
-0.7163\end{array}$ & $\begin{array}{l}(-0.4103 ; 0.0225) \\
(-1.1429-0.2896)\end{array}$ \\
\hline & \multirow{2}{*}{\multicolumn{12}{|c|}{ Mother's education level $\mathrm{d}$}} \\
\hline High school or Technical diploma & 356.6636 & $(166.3338: 546.9935)$ & 82.6197 & $(-90.323 \cdot 255.5625)$ & 4.36 & $(1.6352 \cdot 7.0994)$ & 0.5 & $(-2)$ & & & & \\
\hline $\begin{array}{l}\text { University or more } \\
\text { Father's education level }\end{array}$ & 504.7291 & $(273.1514 ; 736.3067)$ & 328.8541 & $(96.5746 ; 561.1$ & 4.9147 & $(1.5905 ; 8.2389)$ & 0.9964 & $(-2.57$ & 0.9769 & $(0.5083 ; 1.4456)$ & 0.6832 & $(0.1536 ; 1.2129)$ \\
\hline High school or Technical diploma & 9.9165 & $(-205.8062 ; 225.6391)$ & 18.636 & $(-161.52$ & 0.5 & $(-2.5062 ; 3.6)$ & 1.3292 & $(-1$ & 0.0059 & $(-0.4314 ; 0.4432)$ & 0.0010 & $(-0.4098 ; 0.4118)$ \\
\hline University or more & 216.7737 & $(1.0510 ; 432.4963)$ & -24.7909 & $(-236.1086 ; 186.5269)$ & 4.5210 & $(1.4212 ; 7.6207)$ & 3.2796 & $(0.0314 ; 6.5278)$ & 0.5324 & $(0.0951 ; 0.9697)$ & 0.0153 & $(-0.4666 ; 0.4971)$ \\
\hline Crowding Index $\mathrm{e}^{\mathrm{e}} \geq 2$ persons/room & -89.8206 & $(-285.3037 ; 105.6626)$ & & & -0.0043 & $(-2.7776 ; 2.7689)$ & & & -0.1206 & $(-0.5063 ; 0.265)$ & & \\
\hline $\begin{array}{l}\text { BMI category } \\
{ }^{1}\end{array}$ & 108.4952 & $(-95.9569: 312.947)$ & & & $3,36>>$ & $(0.475)$ & & & 013 & $(-0.2666$ & & \\
\hline Obese & 188.1952 & $(-111.4817 ; 487.8722)$ & & & 2.1345 & $(-2.1071 ; 6.3761)$ & & & 0.1234 & $(-0.4721: 0.719)$ & & \\
\hline
\end{tabular}

Abbreviations: GHG: greenhouse gases. Numbers in bold are statistically significant ( $p$-value $\leq 0.05) .{ }^{a}$ compared to $1997 ;{ }^{b}$ compared to males; ${ }^{c}$ compared to Beirut and Mount Lebanon;

${ }^{\mathrm{d}}$ compared to intermediate level or less; ${ }^{\mathrm{e}}$ compared to $<2$ persons/room; ${ }^{\mathrm{f}}$ compared to normal weight/underweight. 


\section{Discussion}

Findings from the present study document significant changes in the diet of Lebanese adolescents over time and indicate that the overall EFPs associated with daily food consumption of Lebanese adolescents increased significantly between 1997 and 2009. Significant changes were also noted in terms of the contribution of various food groups to the EFPs investigated, including water use, energy use and GHG emissions.

The total water use from the food consumption reported in the present study in both survey years (1908.28 \pm 52.43 and $2358 \pm 62.49 \mathrm{~L} /$ day) were within the average global range for total water use estimated from human diets per capita ( 688 to $8341 \mathrm{~L} / \mathrm{d}$ ) [37]. In addition, the total water use estimates in Lebanon were only slightly lower than the total water use from the "average" diet of Asian countries (2862 L/d per capita), including China, India, and other Middle Eastern countries [37]. Nevertheless, the increase in water footprint of the diet over time, as estimated in the present study, raises concerns for Lebanon and similar neighboring countries in the region that are water-stressed and are projected to witness further deterioration in their natural resources due to climate change-associated droughts and other environmental threats [38-40]. Similar to water use, an increase in energy use and GHG emissions were noted between 1997 and 2009 based on the food consumption in the study sample. In fact, energy use increased by $23.7 \%$ per day and $15.6 \%$ per $1000 \mathrm{kcal}$, while the GHG emissions increased by $21.6 \%$ per day and $12.7 \%$ per $1000 \mathrm{kcal}$ in the present study. These changes can be attributed in part to the substantial population growth (by over 85\%) witnessed in Lebanon from 1990-2011 in comparison to the increase in global population (approximately $32 \%$ ) over that time period [41].

The upward trend in the overall EFPs from food consumption observed between the two survey years in the present study was also complemented with significant increases in water, energy, and carbon footprints' contributions of various food groups, such as breads and cereals, white meat (poultry, fish), SSBs, salty snacks, added fats and oils, even after adjusting for energy intake. On the other hand, all EFPs associated with milk and fruits consumption among the study sample decreased significantly in 2009 compared to 1997. These findings can be explained by the remarkable shift in dietary intake of Lebanese adolescents reflected through a significant decrease in milk and fruits consumption between 1997 and 2009. Concomitantly, the intakes of meat, poultry, salty snacks, added fats and oils increased within the same time period. The dietary changes observed in the present study were found to be consistent with previous studies indicating a rapid nutrition transition among Lebanese adolescents that is manifested through the adoption of a more Westernized dietary pattern and a lower adherence to the 'traditional' or 'Lebanese-Mediterranean' diet [19,42]. The Western pattern has been previously characterized by the high consumption of red meat, poultry and eggs, pizzas, pies and fast-food sandwiches, while the Lebanese-Mediterranean pattern reflected high intakes of fruits, vegetables, legumes, whole grains, fish and olive oil [19]. More recently, Naja et al. (2018) explored the EFPs for dietary patterns commonly adopted among Lebanese adults and their findings further point to the higher carbon and water footprints of 'Western and 'High-Protein' patterns, compared to the Lebanese-Mediterranean diet [(water use (L/1000 kcal/day: 443.61 vs. 264.72 vs. 243.35), GHG ( $\mathrm{kg} \mathrm{CO} 2$ eq/1000 kcal/day: 0.58 vs. 0.57 vs. 0.38)] [31].

In addition, the study findings show that the meats group, which includes red meat, organ meat, and other meat-based dishes, was among the top contributors to the increase in overall EFPs (approximately $20 \%$ contribution). More specifically, the meats group contributed the most to total water use with approximately $8939 \mathrm{~L}$ used per $\mathrm{kg}$ consumed, and it had the highest contribution to GHG emissions in the analysis (20.4kg CO2eq $/ \mathrm{kg}$ ) compared to all other food groups (S1). These estimates were in line with other studies highlighting animal-based food products, particularly meat consumption, as the lead contributors to total water use and GHG emissions [43-45]. According to Mekonnen and Hoekstra (2012), animal products have a large water footprint relative to crop products with equivalent nutritional value, for example the average water footprint per calorie for beef is 20 times larger than for cereals and starchy roots [43]. Another study exploring the water footprint of meat-producing systems in different countries (China, Brazil, the US and the Netherlands) concluded that overall beef has the 
largest total water footprint followed by pork and poultry [44]. In terms of GHG emissions, a study conducted in the US to assess the environmental impact of individual self-selected diets of adults using NHANES data, showed that the meats group contributed to $57 \%$ of dietary GHG emissions with $80.6 \%$ of these emissions coming from beef and the remainder coming from poultry $(9.5 \%)$, pork $(8.5 \%)$, and other sources (1.5\%) [45].

It is worth noting that SSBs as well as breads and cereals were also amongst the five largest contributors to the changes in EFPs among adolescents in the present study. Although grains are not known to have a particularly high environmental impact, the high consumption of bread and grain-based dishes as staple foods in Lebanon [46] may explain their elevated contribution to EFPs. As for SSB, the significant increase in average daily consumption between 1997 and 2009 years can partly explain the contribution of these food groups to the increase in EFPs over the years. The high consumption of soft drinks and sweetened fruit juices is, indeed, a worldwide phenomenon amongst adolescents [47,48], and it has been associated with lower intakes of water, milk, and other nutrient-rich foods, such as fruits and vegetables [49]. In Lebanon, limited studies have examined SSB consumption over time, yet recent evidence has shown the high contribution of soft drinks and fruit juices to water and energy intake among children (4-13 years old), with soft drinks being identified as the lead contributor to total energy intake, particularly amongst the older age group (9- to 13-year-olds), compared to all other caloric beverages including milk, fruit juices, and hot beverages [50]. Another study conducted among Lebanese adolescents (aged 12-18 years) showed that soft drinks consumption was a frequent drinking behavior with approximately $43 \%$ of girls and $56 \%$ of boys consuming these beverages 4-7 times per week or more [51]. These consumption patterns are worrisome given the high environmental footprints of these beverages. In fact, beverages, such as carbonated drinks, sweetened juices, alcoholic beverages, were found to be the third highest contributors of GHG emissions (5.9\%) and non-renewable cumulative energy demand (16\%) within US diets [45]. Other studies have also estimated the high water footprint of sweetened fruit juices and sodas that can range between 200-230 L of water per $200 \mathrm{~mL}$ glass of apple or orange juice [52] and between 150 to $300 \mathrm{~L}$ of water per $0.5 \mathrm{~L}$ of sugar-containing sodas [53].

Results from the linear regression models further highlight the significant increase in all EFP estimates between the two survey years (1997 and 2009), even after adjusting for total energy intake of the study sample, as well as other sociodemographic characteristics. Overall, the study findings indicate an alarming trend over time whereby the change in EFPs was accompanied with a shift in the food consumption behavior of Lebanese adolescents reflected through an increase in meat, poultry, SSB, and added fats/oils intake coupled with significant decreases in consumption of fruits and milk. These findings suggest that Lebanese adolescents are shifting away from the traditional Lebanese dietary pattern, which was described as a variant of the Mediterranean diet [19], towards a more animal-based and highly processed Western-like diet that has been associated with increased risk of obesity and diet-related diseases [54-56]. In fact, the observed trend in Lebanon is neither aligned with the national dietary guidelines nor with the global sustainable development agenda that promote the plant-based Mediterranean diets as vivid examples for "sustainable diets" known for their low environmental impact, health and nutritional value, as well as economic fairness and cultural acceptability [57]. Several reviews were conducted to date highlighting the positive impact of shifting "average diets" or current consumption behaviors to healthier and environmentally more sustainable dietary patterns, including the Mediterranean and vegetarian diets. For example, Aleksandrowicz et al. (2016) showed that reductions above $70 \%$ of GHG emissions and land use, and $50 \%$ of water use, could be achieved by shifting typical Western diets consumed in high income countries to more environmentally sustainable dietary patterns [58]. In addition, the reduction in environmental footprints were generally proportional to the degree to which animal-source foods were being restricted in the recommended diets $[37,58]$. Another global systematic review focusing primarily on the water footprint of diets consumed in different high- and low- to middle-income countries showed that changing from "average diet" to healthier dietary patterns, can reduce total water use by $6 \%(95 \%$ CI: $-7.9,-4.2)$. 
The regression models also showed that being a female adolescent was associated with lower carbon footprint, whereas adolescents with higher maternal educational levels were associated with higher water and carbon footprints. The higher adherence of female adolescents to the plant-based traditional Lebanese pattern with low red meat, as previously reported by Naja et al. (2015), may explain their lower carbon footprint compared to males. On the other hand, the positive associations between maternal education with increased water and carbon footprints of adolescents' dietary intakes did not corroborate findings from other studies that show higher educational levels at the individual and household level to increase adherence to the Mediterranean diet [19,59], the latter diet being known for its overall low environmental impact [32,60]. Nevertheless, our findings need to be interpreted in light of the growing literature illustrating the complex socioeconomic, environmental, and individual-lifestyle factors that play a role in the transition away from the traditional Mediterranean diet [42,61], including potentially higher costs of healthy food items such as fruits, vegetables, and nuts [5,62-65], the aggressive marketing of cheaper yet energy-dense foods and beverages [66,67], as well as increased urbanization, modernization and fast food culture [61]. In addition, and in light of the recent evidence highlighting that healthy and sustainable diets, such as the EAT-Lancet reference diets, may be not affordable for the world's low-income populations (costing on average 60\% more than least-cost options to achieve adequate nutrient intakes), further research is required to explore what interventions or combinations of interventions are needed to promote sustainable and affordable diets among youth in low- to middle-income countries undergoing a rapid nutrition transition.

\section{Strengths and Limitations}

The present study examined the change in food consumption of adolescents over a span of 12 years using individual-level data and evaluated the impact of dietary shifts on several environmental footprints. To date, most of the studies examining the environmental impact of human diets have been focused primarily on population-level intake, particularly adults, yet trends in dietary intake amongst sub-population groups including adolescents are extremely limited [58]. This age group is equally challenging and unique, as it presents a window of opportunity that needs to be explored given the implications of the adolescents' food consumption behaviors on future efforts for promoting more sustainable, healthy, and food-secure populations. Nevertheless, the present study has a few limitations worth considering. The LCAs of the food items within the present study were over a domain spanning from cradle to point-of-sale. The LCAs do not take into account factors such as retail storage and waste, consumer transport to/from the retail store, home storage, preparation method, consumer waste and recycling, and product end of life (for example, land fill, incineration, etc.). All of these downstream factors can significantly alter a food item's EFP as calculated by an LCA. In addition, the EFPs considered in the present study do not address other environmental and ecological footprints that may be worth exploring in the future, including soil erosion, land use, water quality, and biodiversity. Also, it is important to not only calculate the EFPs of human diets, but to also assess the various tradeoffs between EFPs that will inevitably occur as food policies meant to guide changes in dietary patterns begin to alter crop mixes and agricultural management practices.

\section{Conclusions}

In conclusion, the significant dietary shifts observed amongst Lebanese adolescents between 1997 and 2009 combined with the associated increase in all EFPs indicate an alarming trend that can threaten the environmental sustainability of Lebanese diets. Alongside the nutrition transition, Lebanon, and similar countries in the EMR, are witnessing significant increases in the prevalence of diet-related diseases; in addition, these countries continue to face major environmental and climate change-induced threats together with prolonged conflicts and massive displacement. Together these nutrition-health, environmental, and political factors are positioning the region to face a 'perfect storm' that threatens the food security of its populations. 
The study findings call for food policies and public health interventions to reduce the increasing strains on the scarce environmental resources in Lebanon and other countries of the EMR. Such interventions would require changes across the food system, including the food value chain and the food environment, to ensure adherence to nutritional recommendations that are healthy, environmentally sustainable, economically feasible and culturally sensitive. In addition, school-based nutrition education programs and community-based interventions are needed to promote the traditional Mediterranean diet as a sustainable diet that is known for its nutrition, health and ecological benefits. Food-based dietary guidelines and nutrition recommendations provided to adolescents, and the larger Lebanese population, can also be revised to take into consideration the trade-offs between nutrition, health, and environmental outcomes. As adolescence represents a critical stage for the establishment of lifelong dietary behaviors, interventions targeting adolescents provide a window of opportunity to improve population health in the EMR in the short and longer terms.

Supplementary Materials: The following are available online at http://www.mdpi.com/2071-1050/12/11/4519/s1: Table S1: Environmental footprints (water, energy, and GHG) of various food groups per $\mathrm{kg}$, Table S2: Daily environmental footprints contributed by various food groups according to survey year in the study population, Lebanon, 1997 and 2009, among adolescents aged 10-19 years, Tables S3-S5: Linear regression for the association between EFP, survey year and sociodemographic characteristics among Lebanese adolescents, including the p-values, focusing on water use (S3), energy use (S4), and GHG emission (S5).

Author Contributions: Conceptualization, F.N. and L.J.; Formal analysis, F.N. and N.A.; Methodology, M.C.C.; Resources, N.H.; Supervision, L.N.; Writing—original draft, F.N., A.E.Z. and L.N.; Writing一review \& editing, N.H. and L.J. All authors have read and agreed to the published version of the manuscript.

Funding: This research was partially funded by the Water-Energy-Food-Health Nexus Renewable Resources (WEFRAH) program at the American University of Beirut. The original surveys were funded by the Lebanese National Council for Scientific Research through its support to the Associated Research Unit on Undernutrition and Obesity in Lebanon, the Training Programs in Epidemiology and Public Health Interventions Network (TEPHINET in the US), and the World Health Organization (WHO)-Lebanon.

Acknowledgments: The authors would like to acknowledge all study participants who were involved in the original surveys. We also want to extent our gratitude to Jeremy Zidek from Futura Food, LLC for his support in the estimating the environmental footprints in this manuscript.

Conflicts of Interest: The authors declare no conflict of interest.

\section{References}

1. Goldstein, B.; Birkved, M.; Fernandez, J.; Hauschild, M. Surveying the environmental footprint of urban food consumption. J. Ind. Ecol. 2017, 21, 151-165. [CrossRef]

2. Behrens, P.; Kiefte-de Jong, J.C.; Bosker, T.; Rodrigues, J.F.; De Koning, A.; Tukker, A. Evaluating the environmental impacts of dietary recommendations. Proc. Natl. Acad. Sci. USA 2017, 114, 13412-13417. [CrossRef] [PubMed]

3. United Nations. Sustainable Development Goal 12: Ensure Sustainable Consumption and Production Patterns. Available online: https://www.un.org/sustainabledevelopment/sustainable-consumption-production/ (accessed on 17 March 2020).

4. Burlingame, B.; Dernini, S. Sustainable Diets and Biodiversity. Available online: http://www.fao.org/3/ai3004e.pdf (accessed on 16 March 2020).

5. Hirvonen, K.; Bai, Y.; Headey, D.; Masters, W.A. Affordability of the EAT-Lancet reference diet: A global analysis. Lancet Glob. Health 2020, 8, e59-e66. [CrossRef]

6. Fanzo, J. Healthy and Sustainable Diets and Food Systems: The Key to Achieving Sustainable Development Goal 2? Food Ethics 2019, 4, 159-174. [CrossRef]

7. Popkin, B.M.; Adair, L.S.; Ng, S.W. Global nutrition transition and the pandemic of obesity in developing countries. Nutr. Rev. 2012, 70, 3-21. [CrossRef] [PubMed]

8. Popkin, B.M. Global nutrition dynamics: The world is shifting rapidly toward a diet linked with noncommunicable diseases. Am. J. Clin. Nutr. 2006, 84, 289-298. [CrossRef] [PubMed]

9. Hallström, E.; Carlsson-Kanyama, A.; Börjesson, P. Environmental impact of dietary change: A systematic review. J. Clean. Prod. 2015, 91,1-11. [CrossRef] 
10. World Health Organizarion (WHO). A Healthy Diet Sustainably Produced. Available online: https: //apps.who.int/iris/bitstream/handle/10665/278948/WHO-NMH-NHD-18.12-eng.pdf?ua=1 (accessed on 16 March 2020).

11. Vanham, D.; Leip, A.; Galli, A.; Kastner, T.; Bruckner, M.; Uwizeye, A.; Van Dijk, K.; Ercin, E.; Dalin, C.; Brandão, M. Environmental footprint family to address local to planetary sustainability and deliver on the SDGs. Sci. Total Environ. 2019, 693, 133642. [CrossRef]

12. Leach, A.M.; Emery, K.A.; Gephart, J.; Davis, K.F.; Erisman, J.W.; Leip, A.; Pace, M.L.; D’Odorico, P.; Carr, J.; Noll, L.C. Environmental impact food labels combining carbon, nitrogen, and water footprints. Food Policy 2016, 61, 213-223. [CrossRef]

13. Sibai, A.M.; Nasreddine, L.; Mokdad, A.H.; Adra, N.; Tabet, M.; Hwalla, N. Nutrition transition and cardiovascular disease risk factors in Middle East and North Africa countries: Reviewing the evidence. Ann. Nutr. Metab. 2010, 57, 193-203. [CrossRef]

14. Aurino, E.; Fernandes, M.; Penny, M.E. The nutrition transition and adolescents' diets in low-and middle-income countries: A cross-cohort comparison. Public Health Nutr. 2017, 20, 72-81. [CrossRef] [PubMed]

15. Keats, E.C.; Rappaport, A.I.; Shah, S.; Oh, C.; Jain, R.; Bhutta, Z.A. The dietary intake and practices of adolescent girls in low-and middle-income countries: A systematic review. Nutrients 2018, 10, 1978. [CrossRef] [PubMed]

16. Collaborators, G.E.M.R.C. Burden of cancer in the Eastern Mediterranean Region, 2005-2015: Findings from the Global Burden of Disease 2015 Study. Int. J. Public Health 2018, 63, 151-164.

17. Salam, R.A.; Hooda, M.; Das, J.K.; Arshad, A.; Lassi, Z.S.; Middleton, P.; Bhutta, Z.A. Interventions to improve adolescent nutrition: A systematic review and meta-analysis. J. Adolesc. Health 2016, 59, S29-S39. [CrossRef]

18. Lipsky, L.M.; Nansel, T.R.; Haynie, D.L.; Liu, D.; Li, K.; Pratt, C.A.; Iannotti, R.J.; Dempster, K.W.; Simons-Morton, B. Diet quality of US adolescents during the transition to adulthood: Changes and predictors. Am. J. Clin. Nutr. 2017, 105, 1424-1432. [CrossRef]

19. Naja, F.; Hwalla, N.; Itani, L.; Karam, S.; Sibai, A.M.; Nasreddine, L. A Western dietary pattern is associated with overweight and obesity in a national sample of Lebanese adolescents (13-19 years): A cross-sectional study. Br. J. Nutr. 2015, 114, 1909-1919. [CrossRef]

20. Nasreddine, L.; Naja, F.; Chamieh, M.C.; Adra, N.; Sibai, A.-M.; Hwalla, N. Trends in overweight and obesity in Lebanon: Evidence from two national cross-sectional surveys (1997 and 2009). BMC Public Health 2012, 12, 798. [CrossRef]

21. Rahim, H.F.A.; Sibai, A.; Khader, Y.; Hwalla, N.; Fadhil, I.; Alsiyabi, H.; Mataria, A.; Mendis, S.; Mokdad, A.H.; Husseini, A. Non-communicable diseases in the Arab world. Lancet 2014, 383, 356-367. [CrossRef]

22. World Health Organizarion (WHO). Noncommunicable Diseases in the Eastern Mediterranean Region. Available online: http://applications.emro.who.int/dsaf/EMROPUB_2016_EN_18977.pdf?ua=1 (accessed on 14 April 2020).

23. Durrell, J. Investing in Resilience: Addressing Climate-Induced Displacement in the MENA Region; ResearchGate: Berlin, Germany, 2018.

24. Borghesi, S.; Ticci, E. Climate Change in the MENA Region: Environmental Risks, Socioeconomic Effects and Policy Challenges for the Future. IEMed Mediterr. Yearb. 2019, 289-292.

25. IFPRI. Why Is the Middle East Hungry? Blame Armed Conflict. Available online: https://www.ifpri.org/ news-release/why-middle-east-hungry-blame-armed-conflict (accessed on 18 March 2020).

26. Melki, I.; Beydoun, H.; Khogali, M.; Tamim, H.; Yunis, K. Household crowding index: A correlate of socioeconomic status and inter-pregnancy spacing in an urban setting. J. Epidemiol. Community Health 2004, 58, 476-480. [CrossRef]

27. Riva, M.; Plusquellec, P.; Juster, R.-P.; Laouan-Sidi, E.A.; Abdous, B.; Lucas, M.; Dery, S.; Dewailly, E. Household crowding is associated with higher allostatic load among the Inuit. J. Epidemiol. Community Health 2014, 68, 363-369. [CrossRef] [PubMed]

28. Nasreddine, L.; Naja, F.; Akl, C.; Chamieh, M.C.; Karam, S.; Sibai, A.-M.; Hwalla, N. Dietary, lifestyle and socio-economic correlates of overweight, obesity and central adiposity in Lebanese children and adolescents. Nutrients 2014, 6, 1038-1062. [CrossRef] [PubMed]

29. Central Administration of Statistics. Household Living Conditions in 1997, a National Survey; Central Administration of Statistics: Beirut, Lebanon, 1998. 
30. Central Administration of Statistics Bureau. Multiple Indicators Cluster Survey Round 3 (MICS3), 2009; Central Administration of Statistics Bureau: Beirut, Lebanon, 2010.

31. Naja, F.; Jomaa, L.; Itani, L.; Zidek, J.; El Labban, S.; Sibai, A.M.; Hwalla, N. Environmental footprints of food consumption and dietary patterns among Lebanese adults: A cross-sectional study. Nutr. J. 2018, 17, 85. [CrossRef]

32. Naja, F.; Itani, L.; Hamade, R.; Chamieh, M.C.; Hwalla, N. Mediterranean Diet and Its Environmental Footprints Amid Nutrition Transition: The Case of Lebanon. Sustainability 2019, 11, 6690. [CrossRef]

33. Food and Agriculture Organization of the United Nations (FAO). FAOSTAT. Available online: http: //www.fao.org/faostat/en/\#data (accessed on 27 April 2017).

34. United Nations. UN Comtrade Database. Available online: https://comtrade.un.org/ (accessed on 26 April 2017).

35. Pfister, S.; Koehler, A.; Hellweg, S. Assessing the environmental impacts of freshwater consumption in LCA. Environ. Sci. Technol. 2009, 43, 4098-4104. [CrossRef] [PubMed]

36. Forster, P.; Ramaswamy, V.; Artaxo, P.; Berntsen, T.; Betts, R.; Fahey, D.W.; Haywood, J.; Lean, J.; Lowe, D.C.; Myhre, G. Changes in atmospheric constituents and in radiative forcing. Chapter 2. In Climate Change 2007; The Physical Science Basis; Cambridge University Press: Cambridge, UK; New York, NY, USA, 2007.

37. Harris, F.; Moss, C.; Joy, E.J.; Quinn, R.; Scheelbeek, P.F.; Dangour, A.; Green, R. The Water Footprint of Diets: A Global Systematic Review and Meta-analysis. Adv. Nutr. Int. Rev. J. 2019, 11, 375-386. [CrossRef] [PubMed]

38. Gassert, F.M.L.; Landis, P.; Reig, M.; Shiao, T. Aqueduct Global Maps 2.0.Working Paper; World Resources Institute: Washington, DC, USA; Available online: https://www.wri.org/resources/data-sets/aqueduct-globalmaps-20 (accessed on 25 March 2020).

39. Varis, O.; Abu-Zeid, K. Socio-Economic and Environmental Aspects of Water Management in the 21st Century: Trends, Challenges and Prospects for the MENA Region. Int. J. Water Resour. Dev. 2009, 25, 507-522. [CrossRef]

40. Food and Agriculture Organization of the United Nations (FAO). Near East and North AfricaRegional Overview of Food Insecurity:Sustainable Agriculture Water Management is Key to EndingHunger and to Climate Change Adaptation. Available online: http://www.fao.org/3/a-i6860e.pdf (accessed on 25 March 2020).

41. United Nations Department of Economic and Social Affairs Population Dynamics. Available online: https://population.un.org/wpp/ (accessed on 16 March 2020).

42. Naja, F.; Itani, L.; Kharroubi, S.; El Harake, M.D.; Hwalla, N.; Jomaa, L. Food insecurity is associated with lower adherence to the Mediterranean dietary pattern among Lebanese adolescents: A cross-sectional national study. Eur. J. Nutr. 2020, 1-12. [CrossRef]

43. Mekonnen, M.M.; Hoekstra, A.Y. A global assessment of the water footprint of farm animal products. Ecosystems 2012, 15, 401-415. [CrossRef]

44. Gerbens-Leenes, P.W.; Mekonnen, M.M.; Hoekstra, A.Y. The water footprint of poultry, pork and beef: A comparative study in different countries and production systems. Water Resour. Ind. 2013, 1, 25-36. [CrossRef]

45. Heller, M.C.; Willits-Smith, A.; Meyer, R.; Keoleian, G.A.; Rose, D. Greenhouse gas emissions and energy use associated with production of individual self-selected US diets. Environ. Res. Lett. 2018, 13, 044004. [CrossRef] [PubMed]

46. Nasreddine, L.; Hwalla, N.; Sibai, A.; Hamzé, M.; Parent-Massin, D. Food consumption patterns in an adult urban population in Beirut, Lebanon. Public Health Nutr. 2006, 9, 194-203. [CrossRef] [PubMed]

47. Singh, G.M.; Micha, R.; Khatibzadeh, S.; Shi, P.; Lim, S.; Andrews, K.G.; Engell, R.E.; Ezzati, M.; Mozaffarian, D.; Nutrition, G.B.O.D.; et al. Global, regional, and national consumption of sugar-sweetened beverages, fruit juices, and milk: A systematic assessment of beverage intake in 187 countries. PLoS ONE 2015, 10, e0214344. [CrossRef] [PubMed]

48. Dereń, K.; Weghuber, D.; Caroli, M.; Koletzko, B.; Thivel, D.; Frelut, M.-L.; Socha, P.; Grossman, Z.; Hadjipanayis, A.; Wyszyńska, J. Consumption of Sugar-Sweetened Beverages in Paediatric Age: A Position Paper of the European Academy of Paediatrics and the European Childhood Obesity Group. Ann. Nutr. Metab. 2019, 74, 296-302. [CrossRef] [PubMed] 
49. Abdel Rahman, A.; Jomaa, L.; Kahale, L.A.; Adair, P.; Pine, C. Effectiveness of behavioral interventions to reduce the intake of sugar-sweetened beverages in children and adolescents: A systematic review and meta-analysis. Nutr. Rev. 2018, 76, 88-107. [CrossRef]

50. Jomaa, L.; Hwalla, N.; Constant, F.; Naja, F.; Nasreddine, L. Water and beverage consumption among children aged 4-13 years in Lebanon: Findings from a National Cross-Sectional Study. Nutrients 2016, 8, 554. [CrossRef]

51. Salameh, P.; Barbour, B.; Issa, C. Obesity associated behavior in adolescents of private schools in Lebanon. Leban. Med. J. 2011, 103, 1-12.

52. Water Footprint Network. Product Gallery. Available online: http://waterfootprint.org/en/resources/ interactive-tools/product-gallery/ (accessed on 26 April 2017).

53. Ercin, A.E.; Aldaya, M.M.; Hoekstra, A.Y. Corporate Water Footprint Accounting and Impact Assessment: The Case of the Water Footprint of a Sugar-Containing Carbonated Beverage. Water Resour. Manag. 2011, 25, 721-741. [CrossRef]

54. Aljefree, N.; Ahmed, F. Association between dietary pattern and risk of cardiovascular disease among adults in the Middle East and North Africa region: A systematic review. Food Nutr. Res. 2015, 59, 27486. [CrossRef]

55. Naja, F.; Nasreddine, L.; Itani, L.; Adra, N.; Sibai, A.; Hwalla, N. Association between dietary patterns and the risk of metabolic syndrome among Lebanese adults. Eur. J. Nutr. 2013, 52, 97-105. [CrossRef]

56. Naja, F.; Hwalla, N.; Itani, L.; Salem, M.; Azar, S.T.; Zeidan, M.N.; Nasreddine, L. Dietary patterns and odds of Type 2 diabetes in Beirut, Lebanon: A case-control study. Nutr. Metab. 2012, 9, 111. [CrossRef] [PubMed]

57. Aboussaleh, Y.; Capone, R.; El Bilali, H. Mediterranean food consumption patterns: Low environmental impacts and significant health-nutrition benefits. Proc. Nutr. Soc. 2017, 76, 543-548. [CrossRef] [PubMed]

58. Aleksandrowicz, L.; Green, R.; Joy, E.J.; Smith, P.; Haines, A. The impacts of dietary change on greenhouse gas emissions, land use, water use, and health: A systematic review. PLoS ONE 2016, 11, e0165797. [CrossRef] [PubMed]

59. Cavaliere, A.; De Marchi, E.; Banterle, A. Exploring the adherence to the Mediterranean diet and its relationship with individual lifestyle: The role of healthy behaviors, pro-environmental behaviors, income, and education. Nutrients 2018, 10, 141. [CrossRef] [PubMed]

60. Sáez-almendros SObrador, B.; Bach-faig, A.; Serra-majem, L. Environmental footprints of Mediterranean versus Western dietary patterns: Beyond the health benefits of the Mediterranean diet. Environ. Health 2013, 12, 118. [CrossRef] [PubMed]

61. Idelson, P.I.; Scalfi, L.; Valerio, G. Adherence to the Mediterranean Diet in children and adolescents: A systematic review. Nutr. Metab. Cardiovasc. Dis. 2017, 27, 283-299. [CrossRef]

62. Tong, T.Y.; Imamura, F.; Monsivais, P.; Brage, S.; Griffin, S.J.; Wareham, N.J.; Forouhi, N.G. Dietary cost associated with adherence to the Mediterranean diet, and its variation by socio-economic factors in the UK Fenland Study. Br. J. Nutr. 2018, 119, 685-694. [CrossRef]

63. Alonso, A.; Pimenta, A.M.; Bes-Rastrollo, M.; Martinez-Gonzalez, M.A.; Sanchez-Villegas, A.; Lopez, C.N. Costs of Mediterranean and western dietary pattern in a Spanish cohort and their relationship with prospective weight change.(Research Report). J. Epidemiol. Community Health 2009, 63, 920.

64. Schröder, H.; Marrugat, J.; Covas, M.I. High monetary costs of dietary patterns associated with lower body mass index: A population-based study. Int. J. Obes. 2006, 30, 1574-1579. [CrossRef]

65. Saulle, R.; Semyonov, L.; La Torre, G. Cost and cost-effectiveness of the Mediterranean diet: Results of a systematic review. Nutrients 2013, 5, 4566-4586. [CrossRef]

66. Truman, E.; Elliott, C. Identifying food marketing to teenagers: A scoping review. Int. J. Behav. Nutr. Phys. Act. 2019, 16, 1-10. [CrossRef] [PubMed]

67. Harris, J.; Heard, A.; Schwartz, M. Older but still vulnerable: All children need protection from unhealthy food marketing. Uconn Rudd Cent. Food Policy Obes. 2014, 27, 202-221.

(C) 2020 by the authors. Licensee MDPI, Basel, Switzerland. This article is an open access article distributed under the terms and conditions of the Creative Commons Attribution (CC BY) license (http://creativecommons.org/licenses/by/4.0/). 